ASIMTOT: JURNAL KEPENDIDIKAN MATEMATIKA

Volume 1 Nomor 2, Juni - November 2019, halaman 111 - 118

Tersedia Daring pada https://journal.unwira.ac.id/index.php/ASIMTOT

\title{
SELF-REGULATED LEARNING PADA ASPEK MOTIVASI SISWA KELAS VIII SMP NEGERI 2 TARAKAN DALAM BELAJAR MATEMATIKA
}

\section{SELF-REGULATED LEARNING ON THE ASPECT OF MOTIVATION OF EIGHTH- GRADE STUDENTS AT SMP NEGERI 2 TARAKAN IN LEARNING MATHEMATICS}

\author{
Putria I. Chaidir, Jero B. Darmayasa \\ Universitas Borneo Tarakan \\ putriailliyyin@gmail.com
}

\begin{abstract}
Abstrak: Beberapa hasil penelitian menunjukkan bahwa adanya pengaruh yang signifikan antara Self-Regulated Learning terhadap hasil belajar matematika siswa. Permasalahannya, dari hasil studi pendahuluan ditemukan banyak siswa yang tidak memiliki Self-Regulated Learning yang bagus, khususnya kelas VIII SMP Negeri 2 Tarakan. Oleh karena itu, penelitian ini bertujuan untuk menemukan bagaimana siswa kelas VIII SMP Negeri 2 Tarakan melatih Self-Regulated Learning dalam belajar matematika pada aspek Motivasi. Jenis penelitian yang digunakan adalah studi kasus dengan pendekatan kualitatif. Penelitian dilaksanakan di SMP Negeri 2 Tarakan dengan subjek penelitian siswa kelas VIII sebanyak 4 orang yang dipilih menggunakan purposive sampling. Pengumpulan data dilakukan dengan observasi, wawancara, dan analisis dokumentasi yang kemudian ditulis dalam catatan lapangan. Data hasil penelitian kemudian direduksi, disajikan, dan ditarik kesimpulan. Berdasarkan hasil penelitian, maka diperoleh bahwa keempat siswa tersebut melatih Self-Regulated Learning dalam belajar matematika pada aspek motivasi dengan cara: 1) menjaga semangat dan keyakinan diri dalam belajar matematika; dan 2) berbagi pengetahuan matematika dengan menjadi tutor sebaya.
\end{abstract}

Kata Kunci: self-regulated learning, motivasi, dan pendidkan matematika.

Abstract: A few research already showed there is a significant effect between Self-Regulated Learning towards students results in learning math. Unfortunately, from initial observation researcher found there are lot of students didn't have good Self-Regulated Learning, specially eighth-grade students of SMP Negeri 2 Tarakan. Therefore, the purpose of this research is to find how eighth-grade students of SMP Negeri 2 Tarakan practice Self-Regulated Learning in learning mathematics on the aspect of motivation. The kind of this research is study case with qualitative approaches. Research was done in SMP Negeri 2 Tarakan with four students of eighthgrade who were selected by using purposive sampling. Data collection is done by observation, interviews, and documentation analysis which is then written in field notes. The results of the research data are then reduced, displayed, and conclusions are drawn. Based on the result of the research it was obtained that the four students practised Self-Regulated Learning in learning mathematics on the aspect of motivation by: 1) keep spirit and and confidence in learning mathematics; and 2) share the mathematics knowledge by becoming a tutor peer.

Keywords: self-regulated learning, motivation, and mathematics education.

Cara Sitasi: Chaidir, I. P., \& Darmayasa, B. J., (2019). Self-Regulated Learning Pada Aspek Motivasi Siswa Kelas VIII SMP Negeri 2 Tarakan Dalam Belajar Matematika. Asimtot: Jurnal Kependidikan Matematika, “1"("2"), “111-118" 
Pendidikan merupakan hal yang sangat penting bagi kehidupan dan kemajuan bangsa. Oleh sebab itu, pemerintah terus berupaya untuk memperbaiki sistem pendidikan di Indonesia, salah satunya dengan meningkatkan kualitas pendidikan. Upaya pemerintah untuk meningkatkan kualitas pendidikan di Indonesia diwujudkan dengan pengembangan kurikulum. Saat ini kurikulum yang sedang diterapkan oleh pemerintah adalah kurikulum 2013. Dalam penerapannya, siswa SMP dituntut memiliki potensi untuk dapat menerapkan berbagai pengetahuan yang dimiliki berdasarkan rasa ingin tahunya. Potensi tersebut dapat dikembangkan dari pelajaran-pelajaran yang didapatkan oleh siswa, salah satunya adalah pelajaran matematika. Dimana matematika adalah suatu mata pelajaran yang wajib dipelajari mulai dari tingkat SD sampai dengan tingkat SMA, bahkan pada perguruan tinggi. Untuk mempelajari dan memahami matematika bukan hal yang mudah. Tidak sedikit orang yang menganggap bahwa matematika adalah pelajaran yang sulit.

Berdasarkan deskripsi aspek pengetahuan pada pembelajaran matematika yang diterapkan di SMP Negeri 2 Tarakan, siswa dikatakan dapat memperoleh nilai $\mathrm{A}$ apabila ia sudah mampu menguasai semua kompetensi dasar. Sedangkan untuk mendapatkan nilai B apabila ia sudah mampu menguasai sebagian besar kompetensi dasar yang telah diajarkan. Namun faktanya, dari daftar nilai rapot siswa diketahui bahwa hanya sebagian kecil siswa di kelas VIII SMP Negeri 2 Tarakan yang bisa mendapatkan nilai A dan B, Oleh karena itu, sangat dibutuhkan strategi yang khusus dalam diri siswa untuk pembelajaran matematika.

Dalam proses pembelajaran, pengelolaan diri dalam belajar atau disebut dengan Self-Regulated Learning merupakan sebuah strategi yang sangat penting. Menurut Ghufron dan Risnawita (2017:57), SelfRegulated Learning merupakan sebuah upaya individu dalam mengelola atau mengatur dirinya untuk belajar dengan mengikutsertakan kemampuan metakognisi, motivasi serta perilakunya. Dalam hal ini peneliti hanya terfokus pada aspek motivasi siswa. Menurut Woolfolk (2009:193), motivasi adalah keadaan internal yang membangkitkan, mengarahkan dan mempertahankan perilaku. Siswa yang memiliki Self-Regulated Learning akan memiliki niat dan kemauan serta mampu mengontrol dirinya dalam belajar sehingga dapat mencapai hasil belajar yang diinginkan. Self-Regulated Learning adalah strategi belajar yang penting dimiliki oleh siswa khususnya dalam pelajaran matematika.

$$
\text { Namun berdasarkan studi }
$$

pendahuluan, peneliti menemukan banyak siswa yang tidak memiliki niat dan kemauan dalam belajar matematika sehingga peneliti mengasumsikan bahwa masih banyak siswa yang tidak memiliki Self-Regulated Learning yang bagus. Namun, peneliti menemukan bahwa ada sebagian kecil siswa yang memiliki usaha dan kemauan belajar yang tinggi, sehingga peneliti menganggap bahwa siswa tersebut memiliki Self-Regulated Learning yang bagus. Oleh karena itu, peneliti ingin mencari tahu lebih mendalam tentang cara siswa tersebut melatih SelfRegulated Learning pada aspek motivasi dalam belajar matematika.

\section{Metode Penelitian}

Jenis penelitian yang digunakan dalam penelitian ini adalah studi kasus dengan 
pendekatan kualitatif. Dalam hal ini peneliti mencari tahu mengenai cara siswa melatih Self-Regulated Learning pada aspek Motivasi dalam belajar matematika dengan melibatkan pengumpulan beraneka sumber informasi. Penelitian ini berlangsung selama tiga bulan tertanggal dari 18 April 2019 sampai dengan 18 Juli 2019. Peneliti menemui subjek penelitian beserta informan di sekolah maupun di rumah subjek pada saat pagi, siang dan sore hari. Wawancara dilakukan dengan subjek penelitian rata-rata satu sampai dengan tiga kali.

Data atau informasi diperoleh dari empat siswa sebagai subjek penelitian yaitu siswa yang memiliki Self-Regulated Learning yang bagus. Pemilihan empat siswa sebagai subjek ini mengacu pada pernyataan Creswell (2014:239) yang menyatakan bahwa "From my review of many qualitative research studies I have found narrative research to include one or two individuals". Peryataan tersebut dapat dimaknai bahwa dari banyaknya penelitian kualitatif diketahui bahwa biasanya peneliti hanya menyertakan satu sampai dua orang sebagai subjek penelitian. Berdasarkan hal tersebut maka semakin sedikit subjek yang diteliti akan dapat memberikan gambaran yang lebih mendalam dibandingkan dengan subjek yang banyak.

Pemilihan subjek dilakukan dengan cara purposive sampling. Pemilihan subjek yang dilakukan dengan purposive sampling ini mengacu pada pernyataan Muhadjir (2011:180) yang menyatakan bahwa purposive sampling dapat dilakukan berdasarkan jaringan yaitu dengan menetapkan sampel berdasarkan informasi dari warga masyarakat objek penelitian. Dalam hal ini peneliti mendapatkan informasi dari hasil observasi dan wawancara dari guru matematika yang mengajar di kelas VIII SMP Negeri 2 Tarakan. Selain siswa yang dijadikan subjek pada penelitian ini, peneliti juga memerlukan beberapa informan untuk menambah data atau informasi mengenai subjek yang akan diteliti. Informan dalam penelitian ini yaitu guru matematika, orang tua dan juga teman dekat siswa.

Teknik pengumpulan data yang dilakukan dalam penelitian ini yaitu melalui observasi, wawancara dan analisis dokumentasi. Dalam penelitian ini, instrumen penelitian adalah peneliti sendiri, namun peneliti menggunakan instrumen pendukung seperti alat perekam wawancara (tape recorder), lembar observasi, catatan lapangan, dan pedoman wawancara. Teknik analisis data yang digunakan dalam penelitian ini menggunakan langkah-langkah analisis data menurut Miles dan Huberman (2014:16) yaitu reduksi data, penyajian data, dan penarikan kesimpulan.

Tahap terakhir dalam penelitian ini yaitu dengan menguji keabsahan data. Uji keabsahan dalam penelitian ini meliputi uji keterpercayaan (credibility) yaitu dengan melakukan triangulasi sumber, waktu, dan teknik serta melakukan member check kepada subjek penelitian. Kemudian uji keteralihan (transferability) yaitu dengan membuat laporan penelitian yang jelas, lengkap dan serinci mungkin agar dapat dipercaya, uji kebergantungan (dependability) yaitu dengan mengajak dosen pembimbing bertemu sumber data untuk mengaudit keseluruhan proses penelitian yang dilakukan oleh peneliti, serta uji kepastian (confirmability) yaitu dengan cara menyusun catatan lapangan, melaporkan proses pengumpulan data dan adanya audit dari dosen pembimbing yang dilakukan bersamaan dengan dependabilitas. 


\section{Hasil Penelitian dan Pembahasan}

\section{Hasil}

Berikut ini adalah data hasil penelitian yang diperoleh melalui proses penelitian dari keempat subjek. Data yang diperoleh juga didukung oleh informasi dari guru, orang tua, dan teman dekat siswa berdasarkan hasil wawancara, observasi dan analisis dokumentasi.

1. Subjek A

Peneliti mewawancarai subjek berinisial A untuk pertama kalinya di sekolah pada saat subjek A sedang tidak ada mata pelajaran dan proses wawancara ini berlangsung di perpustakaan SMP Negeri 2 Tarakan. Peneliti menanyakan tentang keyakinan subjek A dalam belajar matematika, berikut cuplikan wawancara peneliti dengan subjek A (18 April 2019, pukul 08.16-09.00):

P :"Bagaimana keyakinan kamu dalam mengerjakan matematika?"

A : "Biasanya yah kalau soalnya susah saya harus percaya kalau saya tuh bisa lewati itu. Percaya ajalah pokoknya."

Kemudian pernyataan tersebut juga didukung dengan cuplikan wawancara peneliti dengan subjek A berikut ini:

\section{P :"Seberapa yakin kamu bisa paham sama materi matematika walaupun itu sesusah apapun?" \\ A : Yah yakin lah bu, caranya ya dengan semangatin diri sendiri, orang tua juga sering semangatin gitu."}

Selain keyakinan, subjek A juga memiliki semangat dalam belajar matematika, berikut cuplikan wawancara peneliti dengan subjek A (21 Juni 2019, pukul 07.15 - 08.10):

$\mathrm{P}$ : "Bagaimana semangat kamu dalam belajar matematika?"

A : "Semangat terus saya bu."

Selain itu, pernyataan tersebut juga didukung dengan hasil observasi pada saat subjek A belajar matematika di dalam kelas (14 Mei 2019, pukul 08.50 - 09.50). Dalam observasi tersebut, subjek A terlihat sangat bersemangat menjawab pertanyaan yang dilontarkan oleh guru.

Kemudian peneliti melakukan wawancara lebih lanjut dan menanyakan apakah subjek A pernah mengajari temantemannya, berikut cuplikan wawancara peneliti dengan subjek A (4 Mei 2019, pukul $10.05-11.00)$ :

$\mathrm{P}$ : "Apakah kamu pernah mengajarin teman kamu belajar matematika?"

A : "Iya bu, sering ada teman datang kerumah juga minta ajarin."

P : "Kemudian kalau di kelas kamu sering ngajarin siapa?"

A : "Saya biasa ngajarin $N, W, J$, sama U. Tapi kadang saya juga nanya ke mereka."

Selain itu, peneliti melakukan wawancara lebih lanjut dan menanyakan apakah subjek A pernah mengajari temantemannya, berikut cuplikan wawancara peneliti dengan subjek A (4 Mei 2019, pukul 10.05 - 11.00): itu, hal ini juga didukung dengan hasil observasi pada saat subjek A belajar matematika di dalam kelas (14 Mei 2019, pukul 08.50 - 09.50). Dalam observasi tersebut, subjek A terlihat memberi tahu dan mengajari teman sebangkunya ketika temannya tersebut bertanya kepada subjek A.

2. Subjek B 
Peneliti mewawancarai subjek berinisial B untuk pertama kalinya di sekolah pada saat subjek B sedang tidak ada mata pelajaran dan proses wawancara ini berlangsung di perpustakaan SMP Negeri 2 Tarakan. Peneliti menanyakan tentang keyakinan subjek B dalam belajar matematika, berikut cuplikan wawancara peneliti dengan subjek B (18 April 2019, pukul 10.16-11.30):

\section{P:"Bagaimana kamu menilai diri kamu bisa dalam mengerjakan matematika?" \\ B: "Yah saya merasa yakin bu. Yah harus semangat pokoknya." \\ P:"Bagaimana cara kamu menyemangati diri kamu?" \\ B:"Nulis-nulis motivasi gitu bu di sticky note, kayak harus bisa gitu nah, pokoknya jadi yang terbaik dari yang terbaik gitu. Terus saya tempel di buku catatan."}

Selain itu, pernyataan tersebut juga didukung dengan hasil observasi pada saat subjek B sedang belajar matematika di dalam kelas (14 Mei 2019, pukul 08.50 - 09.50). Dalam observasi tersebut, subjek B terlihat bersemangat menjawab pertanyaan yang dilontarkan oleh guru.

Kemudian peneliti melakukan wawancara lebih lanjut dan menanyakan apakah subjek B pernah mengajari matematika kepada temannya, berikut cuplikan wawancara peneliti dengan subjek B (4 Mei 2019, pukul 11.05-12.10):

$\mathrm{P}:$ "Kamu sering nda ajarin teman kamu belajar matematika?"

B: "Iya bu, lumayan sering, biasa saya ajarkan $G$ sama $H$ bu, W juga suka tanya ke saya. Tapi kadang saya tanya juga ke mereka."
Selain itu, pernyataan tersebut juga didukung dengan hasil observasi pada saat subjek B belajar matematika di dalam kelas (14 Mei 2019, pukul 08.50 - 09.50). Dalam observasi tersebut, subjek B terlihat mengajari teman sebangkunya pada saat temannya tersebut bertanya kepada subjek B.

\section{Subjek C}

Peneliti mewawancarai subjek berinisial $\mathrm{C}$ untuk pertama kalinya di sekolah pada saat subjek $\mathrm{C}$ sedang tidak ada mata pelajaran dan proses wawancara ini berlangsung di perpustakaan SMP Negeri 2 Tarakan. Peneliti menanyakan mengenai keyakinan subjek C dalam belajar matematika, berikut cuplikan wawancara peneliti dengan subjek C: (24 April 2019, pukul 15:15 - 17:00):

P:"Bagaimana kamu meyakini kemampuan kamu dalam belajar matematika?"

C: "Yakin aja bu. Tapi kadang pernah ragu-ragu juga."

P:"Apakah kamu pernah putus asa nda jika mendapatkan soal matematika yang sulit untuk dikerjakan?"

C:"Nda pernah putus asa. Harus semangat. Kalau kerjakan soal juga nda pernah kosong. Paling kerjakan aja usaha, kalau pilihan ganda cari jawaban yang mendekati."

Selain itu, pernyataan tersebut juga didukung dengan hasil observasi pada saat subjek $\mathrm{C}$ belajar matematika di dalam kelas (14 Mei 2019, pukul 11.00 - 12.00). Dalam observasi tersebut terlihat pada saat guru melontarkan pertanyaan kepada semua siswa, subjek C menjawab dengan lantang dan bersemangat. 
Kemudian peneliti melakukan wawancara lebih lanjut dan menanyakan apakah subjek $\mathrm{C}$ pernah mengajari matematika kepada temannya, berikut cuplikan wawancara peneliti dengan subjek C (24 April 2019, pukul 15:15 - 17:00):

\section{P:"Apakah kamu pernah mengajari matematika kepada teman- temanmu?" \\ C:"Oh sering aja bu. Yang biasa minta ajarin tuh $Z, K, X$, sama $R$ bu."}

Selain itu, pernyataan tersebut juga didukung dengan hasil observasi pada saat subjek C belajar matematika di dalam kelas (14 Mei 2019, pukul 11.00 - 12.00). Dalam observasi tersebut, subjek $\mathrm{C}$ terlihat memberi tahu dan mengajari ketika teman sebangkunya tersebut bertanya kepada subjek C.

\section{Subjek D}

Peneliti mewawancarai subjek berinisial D untuk pertama kalinya di sekolah pada saat subjek D sedang tidak ada mata pelajaran dan proses wawancara ini berlangsung di perpustakaan SMP Negeri 2 Tarakan. Kemudian lebih lanjut peneliti menanyakan tentang keyakinan subjek D dalam belajar matematika, berikut cuplikan wawancara peneliti dengan subjek D:

\section{P:"Bagaimana keyakinan kamu dalam mengerjakan matematika?" \\ D: "Iya bu yakin." \\ P:"Pernah nda kamu berputus asa ketika kesulitan mengerjakan matematika?" \\ D: "Nda pernah putus asa bu alhamdulillah, selalu semangat."}

Selain itu, pernyataan tersebut juga didukung dengan hasil observasi pada saat subjek D belajar matematika di dalam kelas (13 Mei 2019, pukul 09.50 - 10.50). Dalam observasi tersebut terlihat pada saat guru melontarkan pertanyaan, subjek D menjawab dengan bersemangat.

Kemudian peneliti melakukan wawancara lebih lanjut dan menanyakan apakah subjek D pernah mengajari temantemannya, berikut cuplikan wawancara peneliti dengan subjek D (12 Mei 2019, pukul $13.40-15.40)$ :

P: "Apakah kamu pernah mengajarin teman kamu belajar matematika?"

D: "Iya bu sering saya ajari, biasa itu X sama T bu."

Selain itu, pernyataan tersebut juga didukung dengan hasil observasi pada saat subjek D belajar matematika di dalam kelas (13 Mei 2019, pukul 09.50 - 10.50). Dalam observasi tersebut, terlihat beberapa kali teman sebangkunya bertanya dan subjek D terlihat memberi tahu dan mengajari temannya tersebut.

\section{Pembahasan}

Berdasarkan hasil penelitian secara keseluruhan, maka ditemukan bahwa subjek yang memiliki motivasi yang paling tinggi yaitu subjek keempat yang berinisial D. Baik sebelum penelitian maupun setelah dilakukannya penelitian, dari awal memang sudah terlihat bahwa subjek D memiliki motivasi yang lebih tinggi dibandingkan dengan subjek lainnya. Motivasi subjek D terlihat dari subjek yang selalu berkeinginan untuk mendapatkan nilai yang tinggi dalam belajar matematika dan selalu menargetkan nilai yang lebih tinggi dibandingkan subjek lainnya.

Kemudian jika dilihat dari keyakinan subjek dalam belajar matematika, subjek A, $\mathrm{B}$, dan $\mathrm{D}$ terlihat memiliki keyakinan dalam 
kemampuan matematikanya. Sedikit berbeda dengan subjek $\mathrm{C}$ yang juga memiliki keyakinan namun terkadang masih ragu dengan kemampuannya. Meskipun subjek C terkadang masih ragu, namun ia tidak pernah berputus asa dalam belajar matematika. Selain memiliki keyakinan, keempat subjek tersebut memiliki semangat dalam belajar matematika. Subjek tetap bersemangat dan tidak pernah berfikir untuk menyudahi proses belajarnya. Hal ini sesuai dengan pernyataan yang dikemukakan oleh Wolters, dkk (2003:10), salah satu strategi yang terdapat dalam aspek Motivasi pada Self-Regulated Learning yatu strategi Performance or extrinsic self-talk yang merupakan suatu keyakinan diri untuk terus melanjutkan kegiatan belajar dan berfikir untuk memperoleh prestasi serta berusaha sebaik mungkin apabila dihadapkan pada kondisi untuk menyudahi proses belajarnya. Dalam hal ini subjek memiliki semangat dan keyakinan dalam belajar matematika.

Kemudian keempat subjek tersebut juga memiliki kesamaan yaitu sering megajari teman-temannya dalam belajar matematika, hal ini menunjukkan bahwa keempat subjek tersebut mampu menguasai matematika dan berbagi pengetahuan matematikanya dengan menjadi tutor sebaya. Hal ini sesuai dengan pernyataan yang dikemukakan oleh Wolters, dkk (2003:10), salah satu strategi yang terdapat dalam aspek motivasi pada SelfRegulated Learning yatu strategi Mastery self-talk yaitu berpikir tentang penguasaan yang berorientasi pada tujuan seperti memuaskan keingintahuan, menjadi lebih kompeten atau meningkatkan perasaan otonomi.

\section{Simpulan dan Saran}

\section{Simpulan}

Berdasakan hasil penelitian, maka dapat disimpulkan bahwa siswa kelas VIII SMP Negeri 2 Tarakan melatih SelfRegulated Learning pada aspek Motivasi dalam belajar matematika dengan cara:

1. Menjaga semangat dan keyakinan diri dalam belajar matematika.

2. Berbagi pengetahuan matematika dengan menjadi tutor sebaya.

\section{Saran}

Berdasarkan kesimpulan di atas, maka dapat diberikan beberapa saran sebagai berikut:

1. Bagi Guru dan Sekolah

Bagi guru dan sekolag diharapkan dapat membimbing Self-Regulated Learning siswa yang sudah terdapat dalam diri siswa maupun yang belum agar dapat berkembang semaksimal mungkin.

2. Bagi Siswa

Bagi siswa diharapkan selalu berupaya untuk menerapkan Self-Regulated Learning dan dapat lebih meningkatkan semangat dan motivasinya agar dapat mencapai hasil belajar yang maksimal.

3. Bagi Peneliti Lain

Bagi peneliti lain diharapkan untuk melakukan penelitian terhadap subjek yang berbeda dari penelitian ini. Pemilihan subjek yang berbeda akan ikut menyumbangkan informasi baru mengenai Self-Regulated Learning.

\section{Daftar Pustaka}

Creswell, John W. (2014). Research Design : Qualitative, Quantitative, and Mixed 
Methods Approaches : Fourth Edition. Sage Publications, Inc.

Ghufron, M. N. dan Rini Risnawita S. (2017). Teori-Teori Psikologi. Jogjakarta: ArRuzz Media.

Miles, M. B. dan Huberman, M. (2014). Analisis Data Kualitatif. Jakarta: Universitas Indonesia.

Muhadjir, Noeng. (2011). Metodologi Penelitian. Yogyakarta: Rake Sarasin.

Wolters, C.A., Pintrich, P.R., dan Karabenick, S.A. (2003). Assesing Academic SelfRegulated Learning. Conference on Indicators of Positive Development: Child Trends.

Woolfolk, Anita. (2009). Educational Psychology Active Learning Edition. Boston: Allyn and Bacon. 